\title{
Randomized, Placebo-controlled, Double-blind, Pilot Trial to Investigate Safety and Efficacy of Cerebrolysin in Patients with Aneurysmal Subarachnoid Hemorrhage
}

Peter Yat-Ming Woo ( $\square$ wym307@ha.org.hk)

Kwong Wah Hospital https://orcid.org/0000-0002-7345-7904

Sandy Lam

Kwong Wah Hospital

Joanna WK Ho (Dr.)

Kwong Wah Hospital

Natalie MW Ko

Kwong Wah Hospital

Ronald PT Li

Kwong Wah Hospital

Leo Jian

Kwong Wah Hospital

Alberto $\mathrm{CH}$ Chu

Kwong Wah Hospital

Marco CL Kwan

Kwong Wah Hospital

Yung Chan

Kwong Wah Hospital

Alain KS Wong

Kwong Wah Hospital

Hoi-Tung Wong

Kwong Wah Hospital

Kwong-Yau Chan

Kwong Wah Hospital

John CK Kwok

Kwong Wah Hospital

Research article 
Keywords: Aneurysmal subarachnoid hemorrhage, Neuroprotection, Neuroregeneration, Delayed ischemic neurological deficit, Vasospasm

Posted Date: December 16th, 2019

DOI: https://doi.org/10.21203/rs.2.18960/v1

License: (1) This work is licensed under a Creative Commons Attribution 4.0 International License. Read Full License

Version of Record: A version of this preprint was published at BMC Neurology on November 3rd, 2020. See the published version at https://doi.org/10.1186/s12883-020-01908-9. 


\section{Abstract}

\section{Background}

There are limited treatment options for aneurysmal subarachnoid hemorrhage (SAH)-induced delayed cerebral ischemia, a major determinant of mortality and morbidity. Cerebrolysin, a brain-specific pleiotropic neuroprotective agent, has been suggested to improve functional outcomes in ischemic stroke. We investigated the efficacy, safety and feasibility of Cerebrolysin for conferring such benefits in SAH patients.

\section{Methods}

This was a prospective, randomized, double-blind, placebo-controlled, single-center, parallel-group pilot study. 50 patients received either daily Cerebrolysin ( $30 \mathrm{ml} /$ day) or a placebo (saline) for 14 days (25 patients per study group). The primary endpoint was a favorable Extended Glasgow Outcome Score (GOSE) of 5 to 8 (moderate disability to good recovery) at six-months. Secondary endpoints included the occurrence of adverse effects, six-month mortality, the occurrence of cerebral vasospasm, delayed cerebral ischemia and infarction.

Results

No severe adverse effects or mortality attributable to Cerebrolysin were observed. No significant difference was detected in the proportion of patients with favorable six-month GOSE in either study group (odds ratio (OR): $0.53 ; 95 \%$ confidence interval $(\mathrm{Cl})$ : 0.43-5.17). Secondary functional outcome measures for good six-month recovery indicated by a modified Rankin Scale of 0 to 2 (OR: 0.53 ; $95 \% \mathrm{Cl} 0.43-5.17$ ) and a Barthel Index of 70 or more (OR: $0.52 ; 95 \% \mathrm{Cl}$ : 0.29-12.72) were also similar for both groups. There was a significantly lower risk of three- and six-month mortality for patients that received Cerebrolysin (OR: $0.46 ; 95 \% \mathrm{Cl}: 0.33-0.63)$. There were no deaths in the Cerebrolysin group, but the morality rate for the control group was $16 \%(4 / 25)$. The commonest cause of death was due to delayed cerebral ischemia. There were no differences in the overall incidence of delayed cerebral ischemia ( $p$-value: 0.78 ), cerebral vasospasm ( $p$-value: 0.16$)$ and infarction ( $p$-value: 0.77$)$ between the two groups.

Conclusions

Use of Cerebrolysin in addition to standard-of-care management of aneurysmal SAH is safe, well tolerated and feasible. Results suggest a benefit in reducing three- and six-month mortality. Due to the exploratory nature of this study and its small sample size, these findings should be confirmed in a largerscale clinical trial.

\section{Background}

Aneurysmal subarachnoid hemorrhage (SAH) accounts for less than $5 \%$ of all stroke, but given the relatively young age of afflicted patients and the severity of brain insult, it is disproportionately 
responsible for $27 \%$ of all stroke-related potential years of life lost before the age of 65.[1] Advances in intracranial aneurysm treatment and neurocritical care have substantially improved outcomes, but delayed cerebral ischemia ( $\mathrm{DCl}$ ) continues to be a management challenge.[2-4] $\mathrm{DCl}$ is a major determinant of mortality, accounting for up to $50 \%$ of all SAH-related deaths, and morbidity in patients that survive the initial hemorrhage.[5, 6] It occurs in $20-40 \%$ of patients, but in spite of its recognition as an important complication of $\mathrm{SAH}$, the exact pathophysiology remains to be elucidated.[7] $\mathrm{DCl}$ is postulated to be a multifactorial process involving blood-brain barrier disruption, arteriolar vasospasm, microthrombosis, loss of cerebrovascular autoregulation, cortical spreading depolarizations and the triggering of inflammatory cascades.[8] Since it usually occurs between four and 10 days after SAH, there exists a potential therapeutic window that has been subject to intensified research.[5] But to-date clinical trials investigating endothelin receptor antagonists such as clazosentan, lipid peroxidation inhibitors such as tirilazad, aspirin, statins, magnesium, hypertensive therapy, and transluminal balloon angioplasty have generally been unsuccessful.[9-16] The only consistently proven treatment for $\mathrm{DCl}$ that can reduce poor clinical outcomes is Nimodipine, a calcium channel blocker, that was identified 30 years ago by Pickard et al and has since been verified by several subsequent trials.[2, 17]

Cerebrolysin (EVER Neuro Pharma GmbH, Unterach, Austria) is an intravenously (IV) administered preparation consisting of a mixture of low-molecular weight neuropeptides of less than $10 \mathrm{kDa}(80 \%)$ and free amino acids (20\%) derived from porcine brain tissue. By addressing multiple targets along the pathophysiological cascade of neuronal cell death, Cerebrolysin has been shown to have neuroprotective properties by promoting anti-apoptosis, counteracting glutamate excitotoxicity, reducing free oxygen radical concentrations, microglial activation and modulating the neuro-inflammatory response in both in vitro and murine ischemic stroke models.[18-25] A multicenter randomized placebo-controlled (RCT) phase III clinical trial that evaluated the therapeutic effects of Cerebrolysin in ischemic stroke patients demonstrated improved three-month functional outcomes.[26] Other RCTs have also supported Cerebrolysin's therapeutic potential for ischemic stroke, enhancing neurocognitive performance, reducing the pulsatility index of the middle cerebral artery (MCA) by transcranial Doppler ultrasound (TCD) and infarct volume by magnetic resonance imaging (MRI).[27-33]

For this prospective randomized, placebo-controlled, double-blind pilot study, we aimed to investigate the effects, safety and feasibility of early Cerebrolysin treatment for patients with aneurysmal SAH.

\section{Methods}

This was an investigator-initiated, single-center randomized, placebo-controlled, double-blind, 1:1 parallelgroup phase lla pilot trial that investigated the effects of Cerebrolysin for consecutive adult patients diagnosed with aneurysmal SAH from 1 February 2014 to 30 June 2018. Clinical research ethics committee approval was obtained (Institutional Review Board number: KW/FR-13-006 (61 - 04)). The trial was registered with ClinicalTrials.gov (NCT01787123) and was conducted according to the Declaration of Helsinki and Good Clinical Practice. All subjects or their legal representatives provided written informed consent. 


\section{Inclusion and Exclusion Criteria}

Patients that fulfilled the study criteria were enrolled by the study investigators. The inclusion criteria were: age 18 to 80 years-old; of Chinese descent; a radiological diagnosis of aneurysmal SAH and that the patient could be randomized within 96 hours of ictus, i.e. before the onset of $\mathrm{DCl}$. Exclusion criteria were: when an unsalveagble disease course was anticipated (death within 48 hours of admission or postresuscitation signs of central or uncal herniation); pre-existing neurological or psychiatric disorders, including stroke, epilepsy and dementia; a pre-SAH disability (i.e. a modified Rankin score (mRS) of $\geq 2$ ); major cardiac, pulmonary, hepatic and renal disease (i.e. creatinine concentration of $>200 \mu \mathrm{mol} / \mathrm{L}$ ); terminal medical illness with a life-expectancy of less than one year; an existing diagnosis of $\mathrm{DCl}$ or vasospasm; an active history of alcohol or illicit drug dependency; previous history of Cerebrolysin exposure; any contraindication for Cerebrolysin administration, including pregnancy, lactation and allergies to its components; or concurrent participation in another clinical trial.

\section{Subject Management, Randomization and Blinding}

After establishing the diagnosis of a ruptured intracranial aneurysm by either computed (CT) tomography angiography or catheter angiography, patients were randomly assigned to receive either intravenous Cerebrolysin (intervention group) or normal saline infusions (placebo group). In prospective studies focused on ischemic stroke, Cerebrolysin dosages varied from 10 to $50 \mathrm{ml}$ per day.[26-28, 30,33] According to two larger Phase III RCTs, a daily dose of $30 \mathrm{ml}$ Cerebrolysin was administered for a duration of 10 to 21 days.[26, 27] It was decided to adopt a similar daily dose for 14 days in order to cover the four to 10-day period where cerebral vasospasm most frequently occurs after SAH.[34] Subjects in the intervention group received $30 \mathrm{ml}$ of IV Cerebrolysin per day for 14 days. Eight-hourly 30-minute IV infusions consisting of $10 \mathrm{ml}$ of Cerebrolysin diluted with saline to a total volume of $100 \mathrm{ml}$ was given. Subjects in the control group received $100 \mathrm{ml}$ of saline every eight hours for the same period. Allocation was performed according to a predefined block randomization plan generated by the Statistical Package for the Social Sciences version 22.0 (SPSS Inc, Chicago, IL, US). A block size of 10 was used and group allocation within each block was conducted with a 1:1 ratio. Assignment instructions were sealed in envelopes and opened after subject recruitment. Patients and study outcome assessors were blinded to group identity while clinicians directly involved in their medical management were aware. Since Cerebrolysin carries a yellow tint, infusion bags were wrapped in opaque plastic and amber-coloured intravenous tubing were utilized for both study groups in order to mask the infusate administered.

All recruited subjects were treated according to the latest 2012 American Heart Association (AHA)/ American Stroke Association (ASA) Guidelines for the Management of Aneurysmal SAH.[35] In the initial phase all patients were treated at the neurocritical care unit with adherence to Class I and Ila recommendations for the management of DCl: four-hourly doses of Nimodipine $60 \mathrm{mg}$ was administered for 21-days, euvolemia was maintained, induction of hypertension was performed if $\mathrm{DCl}$ was diagnosed and intra-arterial vasodilator therapy was performed in patients with symptomatic cerebral vasospasm 
unresponsive to hypertensive therapy.[35] When considered fit for post-stroke rehabilitation, all subjects were enrolled into a minumum two-week standardized early inpatient mobilisation physiotherapy program and occupational therapy for basic activities of daily living.

\section{Data Collection and Study Endpoint Assessment}

Data from clinical records, operation notes, medication dispensing records, laboratory and radiological investigations were collected by an independent neurosurgeon without knowledge of the subject group assignment. The clinical severity of SAH was classified according to the modified World Federation of Neurosurgical Societies (WFNS) grading scale.[36] Good-grade WFNS was defined as grade I or II, i.e. patients presenting with a GCS of 14 or 15. The Acute Physiology and Chronic Health Evaluation (APACHE II) score, an independent predictor for inhospital mortality for SAH patients, was also calculated. [37] The Charlson Comorbidity Index (CCl), a validated prognostic system for ischemic stroke patients, comprising of a weighted score of 17 comorbidities based on the International Classification of Diseases, Ninth Revision, was determined.[38, 39] The degree of SAH on the first CT brain scan was evaluated according to the modified Fisher's grading and Hijdra scoring systems by another independent neurosurgeon.[40,41] The Hijdra system consists of a semiquantitative assessment of the amount of blood identified in 14 regions of interest with a score of $\geq 22$ being recently identified as an independent predictor for poor functional outcome, i.e. a modified Rankin score (mRS) of 4 to 6, at six-months.[42]

Functional outcome was evaluated by an independent nurse, without knowledge of the subject's group assignment, at 30 days, three months and six months after ictus using the following instruments: the Extended Glasgow Outcome Scale (GOSE), mRS (modified Rankin Scale) and the Barthel Index (BI). The primary endpoint was favorable GOSE performance, defined as grades 5 to 8 (moderate disability to good recovery), at six months after ictus. Multiple secondary study endpoints were also evaluated by an independent nurse for mRS, BI, neurocognitive function and quality of life at 30 days, three- and sixmonths. Good recovery was defined as a six-month mRS of 0 to 2 (asymptomatic to slight disability) and a six-month BI of 70 to 100 (mildly dependent to independent). Neurocognitive performance was evaluated by the Montreal Congitive Assessment (MOCA) and the Neurobehavioural Cognitive State Examination (NCSE) also at the same time points. Quality of life (QoL) was appraised by adopting the Chinese version of the 36-item Short Form Health Survey questionnaire (SF-36) and the Stroke-specific QOL Scale (SS-QOL). The occurrence of cerebral vasospasm, DCl and radiological evidence of cerebral infarction (unrelated to the primary aneurysm treatment) were determined by an independent neurosurgeon and neuro-radiologist. Cerebral vasospasm was defined as angiographically detectable moderate-to-severe arterial narrowing not attributable to atherosclerosis, catheter-induced spasm or vessel hypoplasia. A TCD reading of the middle cerebral artery (MCA) with a mean velocity of > $120 \mathrm{~cm} / \mathrm{sec}$ or a Lindegaared ratio (MCA: internal carotid artery mean velocity) of $>3$ was also interpretated as indicative of cerebral vasospasm.[6] DCl was defined as a decrease in GCS of $\geq 2$ points or the development of focal neurological deficit for at least one hour not related to post-treatment complications, rebleeding, hydrocephalus, infection, electrolyte or metabolic disturbances according to 
Vergrouwen et al.[5] SAH-related cerebral infarction was defined as CT or MRI evidence of such within six weeks of ictus, that was absent on scans performed 24 to 48 hours after aneurysm occlusion and was not related to the neurosurgical procedure.[5] Finally, 30-day mortality, three- and six-month mortality were also recorded.

\section{Safety Evaluation}

Cerebrolysin-related severe adverse effects (SAEs) are rare. They are defined as hypersensitivity reactions such as anaphylactic shock, seizures and acute renal failure.[43] Other AEs are generally infrequent, transient and mild: agitation, headache, vertigo, gastrointestinal symptoms such dyspepsia, diarrhea, constipation, nausea and vomiting.[43] Patients assigned to receive Cerebrolysin were monitored by the treating clinician for any changes in vital signs as well as in their general physical and neurological examinations. Laboratory tests were also evaluated for abnormalities attributable to Cerebrolysin. If SAEs occurred the decision for premature trial termination was made by study investigators.

\section{Statistical Analysis}

Since the treatment effects of Cerebrolysin in aneurysmal SAH are unknown, to determine the sample size for this pilot study, trials focused on ischemic stroke were used as a reference. The largest phase III trial for Cerebrolysin in ischemic stroke determined that a sample size of 990 subjects, with an a-level of 0.025 (one-sided) and $90 \%$ power, was required to detect treatment superiority over standard care alone for functional performance at three months.[27] By adopting a Bayesian decision-theoretic approach, it was proposed that phase II trials should have a sample size approximately 0.03 times that of a subsequent phase III study, which in this case would be $30(=990 \times 0.03)$ subjects in total.[44] However, it was ultimately decided to increase the sample size to 50 subjects since Sim et al advocated that this number was the absolute minimum required to decide on whether to proceed with a main RCT with a $5 \%$ two-tailed a-level and $80 \%$ power.[45] All analyses were performed on a modified intention-to-treat basis where the last available observed outcome measure was carried forward to handle missing data. Prespecified subgroup analyses were performed for age ( $\geq 65$ or $<65$ years), pre-existing hypertension, modified WFNS grade (good grade: I, i.e. an admitting GCS of 15 or II, i.e. GCS of 14 versus poor grade: III, i.e. GCS 13; IV, i.e. GCS 7-12 or V, i.e. GCS 3-6), modified Fisher grading (I, II or III, IV), aneurysm location (anterior or posterior circulation) and treatment modality (endovascular therapy or clipping). The reporting of this study was in accordance with the recommendations outlined in the Consolidated Standards of Reporting Trials (CONSORT) statement.[46] Statistical tests included logistic regression, the chi-squared test, independent t-test and the Wilcoxin Mann-Whitney U-test. An a-level of 0.05 was used to define statistical significance. Tests were performed by either using Statistical Package for the Social Sciences software version 20.0 (SPSS Inc., Chicago, Illinois, USA) or R version 3.3.2 (R Foundation for Statistical Computing, Vienna, Austria).

\section{Results}


A total of 142 patients were diagnosed with aneurysmal SAH between 1 February 2014 and 26 June 2018. The most frequent reason for exclusion was unsalvageable neurological presentation $(27,19 \%)$ followed by the patient's age being older than 80 years $(18,13 \%)$ and delayed neurosurgical treatment beyond 96 hours after ictus $(14,10 \%)$ (Fig. 1). Among them 50 patients $(35 \%)$ were enrolled into the pilot study with 25 assigned to the intervention or control groups respectively. All patients completed 14 days of Cerebrolysin administration, none withdrew from the study prematurely and there were no study protocol violations. Signficant baseline characteristic differences between the two groups were not detected (Table 1). The mean time from ictus to Cerebrolysin or placebo infusion was $29.4 \pm 14.8$ hours. The mean age was 53 years \pm 10 (range: $34-78$ years) with a male: female ratio of 1:2. The median modified WFNS grade was II and the majority of patients presented with good-grade $\mathrm{SAH}(30,60 \%)$ with a mean APACHE II score of $10 \pm 5$. Regarding the amount of SAH on the initial CT scan, the median modified Fisher grade was III and the mean Hijdra score was $17 \pm 7$. Most intracranial aneurysms were located at the internal carotid artery (ICA) $(21,42 \%)$ followed by the anterior communicating artery (AComA) $(12,24 \%)$ and the middle cerebral artery (MCA) $(10,20 \%)$. The majority of patients underwent endovascular therapy $(35,70 \%)$ and the remaining were treated by clipping. No SAEs or mortality attributable to Cerebrolysin administration was observed. The drug did not interfere with standard-of-care management of aneurysmal SAH patients. 
Table 1

Baseline Characteristics of Patients in the Cerebrolysin and Placebo Groups

\begin{tabular}{|c|c|c|c|}
\hline & $\begin{array}{l}\text { Cerebrolysin } \\
n=25(\%)\end{array}$ & $\begin{array}{l}\text { Normal Saline } \\
n=25(\%)\end{array}$ & P-value \\
\hline \multicolumn{4}{|l|}{ Patient Factors } \\
\hline $\begin{array}{l}\text { Age, mean } \pm S D \text { (range), years } \\
\geq 65 \text { years }\end{array}$ & $\begin{array}{l}52 \pm 9(31-65) \\
2(8)\end{array}$ & $\begin{array}{l}54 \pm 11(37-70) \\
4(16)\end{array}$ & $\begin{array}{l}0.72 \\
0.67\end{array}$ \\
\hline Female & $16(64)$ & $18(72)$ & 0.76 \\
\hline Smoker & $12(48)$ & $9(36)$ & 0.39 \\
\hline Drinker & $1(4)$ & $4(16)$ & 0.35 \\
\hline Pre-existing hypertension & $11(44)$ & $5(20)$ & 0.07 \\
\hline Baseline MAP, mean $\pm \mathrm{SD}, \mathrm{mmHg}$ & $127 \pm 28$ & $122 \pm 22$ & 0.45 \\
\hline Median CCl & 1 & 1 & 1.00 \\
\hline \multicolumn{4}{|l|}{ Disease Factors } \\
\hline $\begin{array}{l}\text { Modified WFNS } \\
\text { I } \\
\text { II } \\
\text { III } \\
\text { IV } \\
\text { V }\end{array}$ & $\begin{array}{l}11(44) \\
4(16) \\
1(4) \\
8(32) \\
1(4)\end{array}$ & $\begin{array}{l}14(56) \\
1(4) \\
3(12) \\
6(24) \\
1(4)\end{array}$ & 0.79 \\
\hline APACHE II score, mean \pm SD & $11 \pm 5$ & $9 \pm 5$ & 0.14 \\
\hline $\begin{array}{l}\text { Modified Fisher CT Grade } \\
\text { I } \\
\text { II } \\
\text { III } \\
\text { IV }\end{array}$ & $\begin{array}{l}3(12) \\
3(12) \\
12(48) \\
7(28)\end{array}$ & $\begin{array}{l}7(28) \\
5(20) \\
6(24) \\
7(28)\end{array}$ & 0.07 \\
\hline $\begin{array}{l}\text { Hijdra score, mean } \pm \text { SD } \\
\text { Hijdra score } \geq 22\end{array}$ & $\begin{array}{l}17 \pm 6 \\
6(24)\end{array}$ & $\begin{array}{l}16 \pm 7 \\
8(32)\end{array}$ & $\begin{array}{l}0.64 \\
0.53\end{array}$ \\
\hline Hydrocephalus & $11(44)$ & $11(44)$ & 1.00 \\
\hline Intraventricular hemorrhage & $10(40)$ & $10(40)$ & 1.00 \\
\hline Intracerebral hemorrhage & $6(16)$ & $6(16)$ & 1.00 \\
\hline Rebleeding & 0 & $1(4)$ & 1.00 \\
\hline
\end{tabular}

N.B. MAP, mean arterial pressure; CCl, Charlson comorbidity index; WFNS, World Federation of Neurosurgical Societies; APACHE; Acute Physiology and Chronic Health Evaluation; IQR, interquartile range; CT, computed tomography; ICA, internal carotid artery; ACA, anterior cerebral artery; AComA, anterior communicating artery; MCA, middle cerebral artery; PC, posterior circulation 


\begin{tabular}{|llll|}
\hline & $\begin{array}{l}\text { Cerebrolysin } \\
\mathbf{n = 2 5}(\%)\end{array}$ & $\begin{array}{l}\text { Normal Saline } \\
\mathbf{n = 2 5}(\%)\end{array}$ & P-value \\
\hline $\begin{array}{l}\text { Aneurysm location } \\
\text { ICA }\end{array}$ & $10(40)$ & $11(44)$ & 0.53 \\
$\begin{array}{l}\text { ACA AComA } \\
\text { PCA }\end{array}$ & $5(20)$ & $9(36)$ & \\
\hline Treatment Factors & $3(12)$ & $2(8)$ & \\
$\begin{array}{l}\text { Aneurysm treatment } \\
\text { Endovascular therapy } \\
\text { Clipping }\end{array}$ & & & 0.11 \\
\hline $\begin{array}{l}\text { N.B. MAP, mean arterial pressure; CCl, Charlson comorbidity index; WFNS, World Federation of } \\
\text { Neurosurgical Societies; APACHE; Acute Physiology and Chronic Health Evaluation; IQR, interquartile } \\
\text { range; CT, computed tomography; ICA, internal carotid artery; ACA, anterior cerebral artery; AComA, } \\
\text { anterior communicating artery; MCA, middle cerebral artery; PC, posterior circulation }\end{array}$ & \\
\hline
\end{tabular}

Analyses were performed according to the original assigned study groups. A larger proportion of patients in the Cerebrolysin group had a favorable GOSE outcome at six months $(76 \%, 19)$ compared to those that received saline $(68 \%, 17)$, but the difference was not significant (OR 1.49; 95\% Cl 0.43-5.17) (Fig. 2 and Table 2). Similar findings were also observed for the six-month functional performance measures for both good $\mathrm{mRS}(0-2)$ and $\mathrm{BI} \geq 70$ (Fig. 2 and Table 2). 
Table 2

A Comparison of Outcomes in the Cerebrolysin and Placebo Groups

\begin{tabular}{|c|c|c|c|}
\hline & $\begin{array}{l}\text { Cerebrolysin } \\
n=25(\%)\end{array}$ & $\begin{array}{l}\text { Normal Saline } \\
n=25(\%)\end{array}$ & $\begin{array}{l}\text { OR }(95 \% \mathrm{Cl}) \\
\text { or P-value }\left(^{*}\right)\end{array}$ \\
\hline $\begin{array}{l}\text { Functional Outcome at } 6 \text { months } \\
\text { GOSE, median (IQR) } \\
\text { GOSE, favorable outcome, i.e. } 5-8 \\
\text { GOSE good outcome, i.e. } 7-8 \\
\text { mRS, median (IQR) } \\
\text { mRS good outcome, i.e. } 0-2 \\
\text { BI, mean } \pm \text { SD } \\
\text { BI } \geq 70\end{array}$ & $\begin{array}{l}7(5-8) \\
19(76) \\
13(52) \\
1(0-3) \\
19(76) \\
91 \pm 28 \\
23(92)\end{array}$ & $\begin{array}{l}7(3-8) \\
17(68) \\
13(52) \\
2(0-4) \\
17(68) \\
90 \pm 24 \\
18(72)\end{array}$ & $\begin{array}{l}\text { NS } \\
0.53(0.43-5.17) \\
1.00(0.33-3.03) \\
\text { NS } \\
0.53(0.43-5.17) \\
0.90^{\star} \\
0.52(0.29-12.72)\end{array}$ \\
\hline $\begin{array}{l}\text { Mortality } \\
\text { 30-day } \\
\text { 3-month } \\
\text { 6-month }\end{array}$ & $\begin{array}{l}0 \\
0 \\
0\end{array}$ & $\begin{array}{l}3(12) \\
4(16) \\
4(16)\end{array}$ & $\begin{array}{l}0.88(0.76-1.02) \\
0.46(0.33-0.63) \\
0.46(0.33-0.63)\end{array}$ \\
\hline Delayed Cerebral Ischemia & $11(44)$ & $12(48)$ & $0.85(0.28-2.59)$ \\
\hline Cerebral Vasospasm & $3(12)$ & $7(28)$ & $0.35(0.08-1.55)$ \\
\hline Cerebral infarction & $14(56)$ & $15(60)$ & $0.85(0.28-2.61)$ \\
\hline $\begin{array}{l}\text { Neurocognitive Performance at } 6 \text { months } \\
\text { MOCA, mean } \pm \text { SD } \\
\text { MOCA } \geq 22 \\
\text { NCSE, within average range } \\
\text { Orientation } \\
\text { Attention } \\
\text { Language comprehension } \\
\text { Repetition } \\
\text { Naming } \\
\text { Constructional ability } \\
\text { Memory } \\
\text { Calculation } \\
\text { Reasoning } \\
\text { Judgment }\end{array}$ & $\begin{array}{l}21 \pm 9 \\
15(60) \\
20(80) \\
21(84) \\
18(72) \\
15(60) \\
11(44) \\
19(76) \\
12(48) \\
19(76) \\
18(72) \\
19(76)\end{array}$ & $\begin{array}{l}21 \pm 8 \\
10(40) \\
18(72) \\
18(72) \\
16(64) \\
10(40) \\
3(12) \\
15(60) \\
9(36) \\
17(68) \\
10(40) \\
18(72)\end{array}$ & $\begin{array}{l}0.98^{*} \\
1.65(0.51-5.33) \\
0.67(0.14-3.19) \\
0.88(0.17-4.43) \\
0.80(0.21-3.04) \\
1.65(0.51-5.33) \\
4.71(1.10-20.00) \\
1.27(0.34-4.74) \\
1.23(0.38-4.00) \\
0.75(0.18-3.10) \\
2.83(1.01-9.61) \\
0.53(0.11-2.43)\end{array}$ \\
\hline $\begin{array}{l}\text { Quality of Life at } 6 \text { months } \\
\text { SF- } 36 \AA \\
\text { Physical health score, mean } \pm \text { SD } \\
\text { Mental health score, mean } \pm \text { SD } \\
\text { SS-QoL, mean } \pm \text { SD } \\
\text { Physical subscore, mean } \pm \text { SD } \\
\text { Psychosocial subscore, mean } \pm \text { SD }\end{array}$ & $\begin{array}{l}77 \pm 23 \\
69 \pm 25 \\
4.5 \pm 0.7 \\
4.6 \pm 0.8 \\
4.2 \pm 0.9\end{array}$ & $\begin{array}{l}74 \pm 26 \\
69 \pm 21 \\
4.5 \pm 0.6 \\
4.5 \pm 0.7 \\
4.4 \pm 0.6\end{array}$ & $\begin{array}{l}0.60^{\star} \\
0.98^{\star} \\
0.98^{\star} \\
0.84^{\star} \\
0.64^{\star}\end{array}$ \\
\hline Adverse Effects & 0 & 0 & NS \\
\hline Length of Hospital Stay, mean \pm SD & $33 \pm 15$ & $39 \pm 32$ & $0.41^{\star}$ \\
\hline \multicolumn{4}{|c|}{$\begin{array}{l}\text { OR, odds ratio; } \mathrm{Cl} \text {, confidence interval; mRS, modified Rankin score; GOSE, extended Glasgow outcome } \\
\text { score; IQR, interquartile range; SD, standard deviation; BI, modified Barthel index; MOCA, Montreal } \\
\text { cognitive assessment; NCSE, Neurobehavioral cognitive state examination; SF-36 } 8 \text {, Short-form } 36 \\
\text { Health Survey; SS-QoL, stroke-specific quality of life; NS, not significant }\end{array}$} \\
\hline
\end{tabular}


30-day all-cause mortality was higher in the saline group $(12 \%, 3)$ than in the Cerebrolysin group where all patients survived, but this was not significant (OR $0.88,95 \% \mathrm{Cl} 0.76-1.02)$. However, a noticeably higher incidence in three- and six-month mortality was observed in saline group patients. $16 \%$ (4) of saline group patients died while none died by these time points in the Cerebrolysin group (both ORs 0.46 ; $95 \% \mathrm{Cl} 0.33-$ 0.63). The cause of death for three of these patients $(75 \%, 3 / 4)$ was due to complications arising from $\mathrm{DCl}$ and the remaining patient died from severe chest infection. A further review of the incidence of inpatient SAH-related complications such as cardiac failure, acute myocardial infarction, renal failure, chest infection, septic shock, pulmonary embolism or gastrointestinal bleeding revealed comparable frequencies of occurence between the two study groups.

Overall, DCl developed in $46 \%$ (23) of patients and the proportion of patients in each group were similar (OR $0.85 ; 95 \% \mathrm{Cl} 0.28-2.59$ ). Similar findings were also noted with regard to cerebral infarction (OR 0.85 ; $95 \% \mathrm{Cl} 0.28-2.61$ ). Cerebral vasospasm was diagnosed in $20 \%$ (10) of all patients, with a higher proportion in the saline group $(28 \%, 7)$ than in the Cerebrolysin group $(12 \%, 3)$, but this did not reach statistical significance (OR $0.35 ; 95 \% \mathrm{Cl} 0.08-1.55)$.

Six-month neurocognitive and QoL assessments were feasible in 80\% (40/50) of communicable patients, $21(84 \%)$ patients in the Cerebrolysin group and $19(76 \%)$ in the saline group. The mean MOCA scores were similar, $21 \pm 9$ in the Cerebrolysin group and $21 \pm 8$ in the saline group (95\% Cl -5.26-5.38). Most of the assessed domains for the NCSE were comparable, but patients in the Cerebrolysin group performed notably better in naming (OR 4.71; 95\% $\mathrm{Cl} 1.10-20.00)$ and in reasoning (OR 2.83; 95\% Cl 1.01-9.61). For six-month QoL assessments, mean SF-36 physical and mental scores as well as the mean physican and psychosocial subscores for SS-QoL were similar for both groups.

Predefined subgroup analyses for favorable six-month GOSE by age (cut-off at 65 years), pre-existing hypertension, WFNS grade, modified Fisher grading, aneurysm location and treatment modality also did not reveal significant superiority for Cerebrolysin (Fig. 3).

\section{Discussion}

The results from this study suggests that Cerebrolysin administration is safe, well tolerated and feasible for aneurysmal SAH patients. Cerebrolysin showed a satisfactory safety profile with no increased incidence of SAEs or mortality. There was also no interference with standard-of-care treatment according to AHA/ASA guidelines and administration within 96 hours of ictus, i.e. before the onset of DCl, was achievable.

One of the major reasons for the recurrent failure of several neuroprotective drug clinical trials to achieve positive outcomes in stroke was the investigation of a single agent's effect on a specific component in the ischemic cascade.[47, 48] In contrast, Cerebrolysin is the only brain-specific pleiotropic drug that targets multiple ischemic pathophysiological events, including counteracting glutamate excitotoxicity, neuroinflammation and apoptosis, due to the combined action of its several constituent neurotrophic factors.[18-25, 49-52] The exact mechanisms of action are unknown, but several preclinical studies 
have suggested that Cerebrolysin not only possesses neuroprotective properties during the acute stroke period, but may also enhance neurorestoration during the post-stroke recovery phase.[24, 26, 28, 32, 53, 54]. For the latter, neuroplasticity manifested by synaptic remodeling and facilitated synaptic transmission have been observed.[52, 55] Murine ischemic stroke model studies have also detected Cerebrolysin-induced neural progenitor cell proliferation at the subventricular zone and neurogenesis with oligodendrogenesis in the peri-infarct zone by activation of the Sonic hedgehog and PI3K/Akt signaling pathways. $[25,49,50]$ To our knowledge this is the first study in the literature to investigate the role of Cerebrolysin for aneurysmal SAH. In addition, no previous Cerebrolysin stroke study has reported the effect of the drug on six-month outcomes despite its asserted neurorestorative potential during the recovery phase.

Neuroprotective stroke trials have often been limited by inappropriately long time-windows for drug administration constituting an additional challenge in translational research.[47, 56] It was hypothesized that for aneurysmal SAH, the early administration of Cerebrolysin before the onset of DCl would have a prophylactic or ameliorating effect that would ultimately improve overall functional outcome. However, with regard to the primary endpoint for favorable six-month GOSE, there was no significant difference in the proportions of patients that received Cerebrolysin from those that had saline ( $p$-value: 0.53 ). A priori subgroup analysis also did not identify patients that would more likely benefit from Cerebrolysin. A trend for lower 30-day mortality was observed for Cerebrolysin group patients ( $p$-value: 0.07 ) and a significant survival benefit was observed for 3 - and 6-month mortality (both p-values: 0.04 ). The cause of death for $75 \%(3 / 4)$ of these patients was due to $\mathrm{DCl}$. But no significant reductions in the overall proportion of patients experiencing $\mathrm{DCl}$ ( $p$-value: 0.78 ), cerebral vasospasm ( $p$-value: 0.16$)$ or infarction ( $p$-value 0.77 ) were noted in Cerebrolysin group patients. The limitation in sample size could not allow for subgroup analysis to detect an association between $\mathrm{DCl}$ and mortality, but $\mathrm{DCl}$ has consistently been proven to be a major independent predictor for survival from several other studies.[5, 7-9, 37] One potential reason for this study's neutral results could be ascribed to underestimation of the impact early brain injury (EBI) which describes the pathophysiological cascade for neuronal cell death immediately following $\mathrm{SAH}$. We believed that administering Cerebrolysin before the onset of DCl would have been sufficiently expeditious, but the concept of EBI has gained precedence as a therapeutic target in recent years.[57] SAH-induced EBI triggers blood-brain barrier dysfunction, inflammation, apopotosis, oxidative stress, cortical spreading depression and excitotoxicity, that can be at least equal or more predictive than $\mathrm{DCl}$ for mortality and morbidity. $[57,58]$ In comparison, investigators of neuroprotective drug trials for ischemic stroke have increasingly advocated the importance of ultra-early intervention within the first four to six hours of symptom onset and even in the prehospital setting. $[47,48,56,57]$ In support of earlier intervention for SAH neuroprotection, Cerebrolysin ischemic stroke RCTs have demonstrated significant improvements in three-month neurological outcomes when the drug was delivered within six hours after hospital admission and within one hour after completing systemic recombinant tissue plasminogen activator thrombolytic therapy.[30, 33] In the present study the mean duration for initiation of Cerebrolysin was 29 hours, well before the development of $\mathrm{DCl}$ which mostly occurs between days 4 and 10 of SAH, but we 
propose that future studies should consider implementing an earlier intervention time-window to account for EBI.[5, 56]

Almost one-fifth of patients $(19 \%, 27)$ were excluded from the study due to the initial clinical judgement that they were unlikely to survive for more than 48 hours or they exhibited signs of brain herniation. This may have led to an over-representation of patients with good WFNS grade SAH $(60 \%, 30)$ and therefore a ceiling effect for favorable GOSE outcome regardless of whether Cerebrolysin was administered. Similar conclusions were reached by investigators of a large multicenter RCT for ischemic stroke that also produced neutral results for Cerebrolysin.[27] A recent meta-analysis also noted that the strongest therapeutic effects of Cerebrolysin were observed in trials with high baseline stroke severity (moderate to severe) as expressed by the National Institues of Health Stroke Scale (NIHSS).[53] Since up to $26 \%$ of patients with poor WFNS grade V SAH can experience good long term mRS (0-2) outcomes we also recommend that subsequent studies consider recruiting patients with more severe SAH by assessing patient eligibility after neurological resuscitation. $[59,60]$

The optimum dose for Cerebrolysin in the setting of aneurysmal SAH requires further investigation. Experimental studies investigating the effect of Cerebrolysin in murine models for focal ischemic stroke noted that a threshold daily dose of $2.5 \mathrm{ml} / \mathrm{kg}$ to $5 \mathrm{ml} / \mathrm{kg}$ was required before significant reductions in infarct volume or improvements in functional outcome could be observed.[23, 25] Apart from one clinical ischemic stroke trial that concluded a daily $50 \mathrm{ml}$ dose of Cerebrolysin for 10 days resulted in better 30day NIHSS scores than a lower dose of $10 \mathrm{ml}$, no other trial has compared different dosing regimens.[29] Even though we adopted a $30 \mathrm{ml}$ daily dose protocol from previous positive ischemic stroke studies, since SAH induces more extensive cerebral ischemia and the minimally-effective weight-based drug dosages discovered from animal studies are considerably higher than that prescribed in human subjects, it is possible that Cerebrolysin group patients may have been undertreated which could have accounted for our neutral findings.

Cognitive dysfunction is gradually being recognized as an important source of disability in SAH survivors occuring in $7-15 \%$ of patients with $\mathrm{DCl}$ being a major predictor.[61, 62] Coupled with the positive clinical results of Cerebrolysin in treating vascular dementia and Alzheimer's disease, we also hypothesized that an improvement in neurocognitive performance could be detected in SAH patients, but no significant difference between the study groups existed. $[63,64]$ This may be due to the relatively short two-week course of administration that was designed to predominantly exploit Cerebrolysin's neuroprotective action. Conversely for dementia RCTs, four- to twelve-week Cerebrolysin regimens were selected to principally harness its neurorestorative capacity. $[63,65]$ Therefore we suggest that subsequent trials may need to incorporate a longer Cerebrolysin exposure duration, for example at least four weeks, to include the post-SAH recovery phase in order to comprehensively assess its potential benefits in neurocognition.

\section{Conclusions}


The findings from this trial support the safety and feasibility of administering Cerebrolysin to aneurysmal SAH patients. Although no significant benefit for functional performance could be detected, there is evidence to suggest that Cerebrolysin reduces three- and six-month mortality. Due to the exploratory nature of this study and its small sample size, these findings should be confirmed in an adequately powered clinical trial to detect group differences in other clinically meaningful endpoints such as $\mathrm{DCl}$ and neurocognitive performance. An earlier time-window for intervention, a longer duration of intervention to encompass the rehabilitation phase and the recruitment of a more homogenous group of moderate to severe WFNS grade (III to V) SAH patients may impart greater insight into Cerebrolysin's therapeutic role.

\section{Abbreviations}

AHA American Heart Association

APACHE Acute Physiology and Chronic Health Evaluation

ASA American Stroke Association

BI Barthel Index

CCI Charlson Comorbidity Index

Cl Confidence interval

CONSORT Consolidated Standards of Reporting Trials

CT Computed tomography

DCI Delayed cerebral ischemia

EBI Early brain injury

GCS Glasgow Coma Scale

GOSE Glasgow Outcome Scale Extended

MCA Middle cerebral artery

mRS Modified Rankin Score

MOCA Montreal Cognitive Assessment

NCSE Neurobehavioural Cognitive State Examination

NIHSS National Institues of Health Stroke Scale

OR Odds ratio 
QoL Quality of Life

RCT Randomized controlled trial

SAE Severe adverse effect

SAH Subarachnoid hemorrhage

SF-36 36-Iten Short Form Health Survey questionnaire

SS-QOL Stroke-specific QOL Scale

TCD Transcranial Doppler

WFNS World Federation of Neurosurgical Societies

\section{Declarations}

\section{ETHICS APPROVAL AND CONSENT TO PARTICIPATE}

Clinical research ethics committee approval was obtained (Hong Kong Hospital Authority, Kowloon West Cluster Institutional Review Board number: KW/FR-13-006 (61-04)). All subjects or their legal representatives provided written informed consent. Patient data was anonymized during the subsequent analysis and dissemination.

\section{CONSENT FOR PUBLICATION}

All authors consented.

\section{AVAILABILITY OF DATA AND MATERIALS}

The datasets acquired and analyzed for this study are available from the corresponding author upon reasonable request.

\section{COMPETING INTERESTS}

The authors declare that they have no competing interests.

\section{FUNDING}

This study did not receive any specific grant from funding agencies in the public, commercial or non-for profit sectors.

\section{AUTHORS' CONTRIBUTIONS}


PW: project execution, manuscript preparation, data acquisition, analysis, interpretation, review and critique. SL, JH, NK, RL and LJ: data acquisition and review. AC, MK, YC, AW, HTW, KYC and JK reviewed and critiqued the manuscript. All authors' have read and approved the manuscript.

\section{ACKNOWLEDGEMENTS}

Not applicable

\section{References}

1. Johnston SC, Selvin S, Gress DR. The burden, trends, and demographics of mortality from subarachnoid hemorrhage. Neurology. 1998;50 5:1413-8; doi: 10.1212/wnl.50.5.1413.

2. Pickard JD, Murray GD, Illingworth R, Shaw MD, Teasdale GM, Foy PM, et al. Effect of oral nimodipine on cerebral infarction and outcome after subarachnoid haemorrhage: British aneurysm nimodipine trial. BMJ. 1989;298 6674:636-42; doi: 10.1136/bmj.298.6674.636.

3. Molyneux AJ, Kerr RS, Yu LM, Clarke M, Sneade M, Yarnold JA, et al. International subarachnoid aneurysm trial (ISAT) of neurosurgical clipping versus endovascular coiling in 2143 patients with ruptured intracranial aneurysms: a randomised comparison of effects on survival, dependency, seizures, rebleeding, subgroups, and aneurysm occlusion. Lancet. 2005;366 9488:809-17; doi: 10.1016/S0140-6736(05)67214-5.

4. Khan AU, Dulhanty L, Vail A, Tyrrell P, Galea J, Patel HC. Impact of specialist neurovascular care in subarachnoid haemorrhage. Clin Neurol Neurosurg. 2015;133:55-60; doi:

10.1016/j.clineuro.2015.03.006.

5. Vergouwen MD, Vermeulen M, van Gijn J, Rinkel GJ, Wijdicks EF, Muizelaar JP, et al. Definition of delayed cerebral ischemia after aneurysmal subarachnoid hemorrhage as an outcome event in clinical trials and observational studies: proposal of a multidisciplinary research group. Stroke. 2010;41 10:2391-5; doi: 10.1161/STROKEAHA.110.589275.

6. Frontera JA, Fernandez A, Schmidt JM, Claassen J, Wartenberg KE, Badjatia N, et al. Defining vasospasm after subarachnoid hemorrhage: what is the most clinically relevant definition? Stroke. 2009;40 6:1963-8; doi: 10.1161/STROKEAHA.108.544700.

7. Schmidt JM, Wartenberg KE, Fernandez A, Claassen J, Rincon F, Ostapkovich ND, et al. Frequency and clinical impact of asymptomatic cerebral infarction due to vasospasm after subarachnoid hemorrhage. J Neurosurg. 2008;109 6:1052-9; doi: 10.3171/JNS.2008.109.12.1052.

8. Budohoski KP, Guilfoyle M, Helmy A, Huuskonen T, Czosnyka M, Kirollos R, et al. The pathophysiology and treatment of delayed cerebral ischaemia following subarachnoid haemorrhage. J Neurol Neurosurg Psychiatry. 2014;85 12:1343-53; doi: 10.1136/jnnp-2014-307711.

9. Velat GJ, Kimball MM, Mocco JD, Hoh BL. Vasospasm after aneurysmal subarachnoid hemorrhage: review of randomized controlled trials and meta-analyses in the literature. World Neurosurg. 2011;76 5:446-54; doi: 10.1016/j.wneu.2011.02.030. 
10. Macdonald RL, Kassell NF, Mayer S, Ruefenacht D, Schmiedek P, Weidauer S, et al. Clazosentan to overcome neurological ischemia and infarction occurring after subarachnoid hemorrhage (CONSCIOUS-1): randomized, double-blind, placebo-controlled phase 2 dose-finding trial. Stroke. 2008;39 11:3015-21; doi: 10.1161/STROKEAHA.108.519942.

11. Kassell NF, Haley EC, Jr., Apperson-Hansen C, Alves WM. Randomized, double-blind, vehiclecontrolled trial of tirilazad mesylate in patients with aneurysmal subarachnoid hemorrhage: a cooperative study in Europe, Australia, and New Zealand. J Neurosurg. 1996;84 2:221-8; doi: 10.3171/jns.1996.84.2.0221.

12. van den Bergh WM, Group MS, Algra A, Dorhout Mees SM, van Kooten F, Dirven CM, et al. Randomized controlled trial of acetylsalicylic acid in aneurysmal subarachnoid hemorrhage: the MASH Study. Stroke. 2006;37 9:2326-30; doi: 10.1161/01.STR.0000236841.16055.0f.

13. Kirkpatrick PJ, Turner CL, Smith C, Hutchinson PJ, Murray GD, Collaborators S. Simvastatin in aneurysmal subarachnoid haemorrhage (STASH): a multicentre randomised phase 3 trial. Lancet Neurol. 2014;13 7:666-75; doi: 10.1016/S1474-4422(14)70084-5.

14. Wong GK, Poon WS, Chan MT, Boet R, Gin T, Ng SC, et al. Intravenous magnesium sulphate for aneurysmal subarachnoid hemorrhage (IMASH): a randomized, double-blinded, placebo-controlled, multicenter phase III trial. Stroke. 2010;41 5:921-6; doi: 10.1161/STROKEAHA.109.571125.

15. Egge A, Waterloo K, Sjoholm H, Solberg T, Ingebrigtsen T, Romner B. Prophylactic hyperdynamic postoperative fluid therapy after aneurysmal subarachnoid hemorrhage: a clinical, prospective, randomized, controlled study. Neurosurgery. 2001;49 3:593-605; discussion -6; doi: 10.1097/00006123-200109000-00012.

16. Zwienenberg-Lee M, Hartman J, Rudisill N, Madden LK, Smith K, Eskridge J, et al. Effect of prophylactic transluminal balloon angioplasty on cerebral vasospasm and outcome in patients with Fisher grade III subarachnoid hemorrhage: results of a phase II multicenter, randomized, clinical trial. Stroke. 2008;39 6:1759-65; doi: 10.1161/STROKEAHA.107.502666.

17. Dorhout Mees SM, Rinkel GJ, Feigin VL, Algra A, van den Bergh WM, Vermeulen M, et al. Calcium antagonists for aneurysmal subarachnoid haemorrhage. Cochrane Database Syst Rev. 2007; 3:CD000277; doi: 10.1002/14651858.CD000277.pub3.

18. Gutmann B, Hutter-Paier B, Skofitsch G, Windisch M, Gmeinbauer R. In vitro models of brain ischemia: the peptidergic drug cerebrolysin protects cultured chick cortical neurons from cell death. Neurotox Res. 2002;4 1:59-65; doi: 10.1080/10298420290007637.

19. Hartbauer M, Hutter-Paier B, Skofitsch G, Windisch M. Antiapoptotic effects of the peptidergic drug cerebrolysin on primary cultures of embryonic chick cortical neurons. J Neural Transm (Vienna). 2001;108 4:459-73; doi: 10.1007/s007020170067.

20. Schauer E, Wronski R, Patockova J, Moessler H, Doppler E, Hutter-Paier B, et al. Neuroprotection of cerebrolysin in tissue culture models of brain ischemia: post lesion application indicates a wide therapeutic window. J Neural Transm (Vienna). 2006;113 7:855-68; doi: 10.1007/s00702-005-0384-3. 
21. Riley C, Hutter-Paier B, Windisch M, Doppler E, Moessler H, Wronski R. A peptide preparation protects cells in organotypic brain slices against cell death after glutamate intoxication. J Neural Transm (Vienna). 2006;113 1:103-10; doi: 10.1007/s00702-005-0302-8.

22. Ren J, Sietsma D, Qiu S, Moessler H, Finklestein SP. Cerebrolysin enhances functional recovery following focal cerebral infarction in rats. Restor Neurol Neurosci. 2007;25 1:25-31.

23. Hanson LR, Liu XF, Ross TM, Doppler E, Zimmermann-Meinzingen S, Moessler H. Cerebrolysin reduces infarct volume in a rat model of focal cerebral ischemic damage. Am J Neuroprotec Neurogen. 2009;1:62-8.

24. Zhang L, Chopp M, Wang C, Zhang Y, Lu M, Zhang T, et al. Prospective, double blinded, comparative assessment of the pharmacological activity of Cerebrolysin and distinct peptide preparations for the treatment of embolic stroke. J Neurol Sci. 2019;398:22-6; doi: 10.1016/j.jns.2019.01.017.

25. Zhang C, Chopp M, Cui Y, Wang L, Zhang R, Zhang L, et al. Cerebrolysin enhances neurogenesis in the ischemic brain and improves functional outcome after stroke. J Neurosci Res. 2010;88 15:327581; doi: 10.1002/jnr.22495.

26. Muresanu DF, Heiss WD, Hoemberg V, Bajenaru O, Popescu CD, Vester JC, et al. Cerebrolysin and Recovery After Stroke (CARS): A Randomized, Placebo-Controlled, Double-Blind, Multicenter Trial. Stroke. 2016;47 1:151-9; doi: 10.1161/STROKEAHA.115.009416.

27. Heiss WD, Brainin M, Bornstein NM, Tuomilehto J, Hong Z, Cerebrolysin Acute Stroke Treatment in Asia I. Cerebrolysin in patients with acute ischemic stroke in Asia: results of a double-blind, placebocontrolled randomized trial. Stroke. 2012;43 3:630-6; doi: 10.1161/STROKEAHA.111.628537.

28. Ladurner G, Kalvach P, Moessler H, Cerebrolysin Study G. Neuroprotective treatment with cerebrolysin in patients with acute stroke: a randomised controlled trial. J Neural Transm (Vienna). 2005;112 3:415-28; doi: 10.1007/s00702-004-0248-2.

29. Skvortsova VI, Stakhovskaia LV, Gubskii LV, Shamalov NA, Tikhonova IV, Smychkov AS. [A randomized, double-blind, placebo-controlled study of Cerebrolysin safety and efficacy in the treatment of acute ischemic stroke]. Zh Nevrol Psikhiatr Im S S Korsakova. 2004; Suppl 11:51-5.

30. Lang W, Stadler CH, Poljakovic Z, Fleet D, Lyse Study G. A prospective, randomized, placebocontrolled, double-blind trial about safety and efficacy of combined treatment with alteplase (rt-PA) and Cerebrolysin in acute ischaemic hemispheric stroke. Int J Stroke. 2013;8 2:95-104; doi: 10.1111/j.1747-4949.2012.00901.x.

31. Chang WH, Park CH, Kim DY, Shin YI, Ko MH, Lee A, et al. Cerebrolysin combined with rehabilitation promotes motor recovery in patients with severe motor impairment after stroke. BMC Neurol. 2016;16:31; doi: 10.1186/s12883-016-0553-z.

32. Gharagozli K, Harandi AA, Houshmand S, Akbari N, Muresanu DF, Vester J, et al. Efficacy and safety of Cerebrolysin treatment in early recovery after acute ischemic stroke: a randomized, placebocontrolled, double-blinded, multicenter clinical trial. J Med Life. 2017;10 3:153-60.

33. Amiri-Nikpour MR, Nazarbaghi S, Ahmadi-Salmasi B, Mokari T, Tahamtan U, Rezaei Y. Cerebrolysin effects on neurological outcomes and cerebral blood flow in acute ischemic stroke. Neuropsychiatr 
Dis Treat. 2014;10:2299-306; doi: 10.2147/NDT.S75304.

34. Weir B, Grace M, Hansen J, Rothberg C. Time course of vasospasm in man. J Neurosurg. 1978;48 2:173-8; doi: 10.3171/jns.1978.48.2.0173.

35. Connolly ES, Jr., Rabinstein AA, Carhuapoma JR, Derdeyn CP, Dion J, Higashida RT, et al. Guidelines for the management of aneurysmal subarachnoid hemorrhage: a guideline for healthcare professionals from the American Heart Association/american Stroke Association. Stroke. 2012;43 6:1711-37; doi: 10.1161/STR.0b013e3182587839.

36. Sano H, Inamasu J, Kato Y, Satoh A, Murayama Y, Diseases WC, et al. Modified world federation of neurosurgical societies subarachnoid hemorrhage grading system. Surg Neurol Int. 2016;7 Suppl 18:S502-3; doi: 10.4103/2152-7806.187491.

37. Lantigua H, Ortega-Gutierrez S, Schmidt JM, Lee K, Badjatia N, Agarwal S, et al. Subarachnoid hemorrhage: who dies, and why? Crit Care. 2015;19:309; doi: 10.1186/s13054-015-1036-0.

38. Fischer U, Arnold M, Nedeltchev K, Schoenenberger RA, Kappeler L, Hollinger P, et al. Impact of comorbidity on ischemic stroke outcome. Acta Neurol Scand. 2006;113 2:108-13; doi: 10.1111/j.1600-0404.2005.00551.x.

39. Charlson ME, Pompei P, Ales KL, MacKenzie CR. A new method of classifying prognostic comorbidity in longitudinal studies: development and validation. J Chronic Dis. 1987;40 5:373-83.

40. Frontera JA, Claassen J, Schmidt JM, Wartenberg KE, Temes R, Connolly ES, Jr., et al. Prediction of symptomatic vasospasm after subarachnoid hemorrhage: the modified fisher scale. Neurosurgery. 2006;59 1:21-7; discussion -7; doi: 10.1227/01.NEU.0000218821.34014.1B.

41. Hijdra A, Brouwers PJ, Vermeulen M, van Gijn J. Grading the amount of blood on computed tomograms after subarachnoid hemorrhage. Stroke. 1990;21 8:1156-61.

42. Woo PYM, Tse TPK, Chan RSK, Leung LNY, Liu SKK, Leung AYT, et al. Computed tomography interobserver agreement in the assessment of aneurysmal subarachnoid hemorrhage and predictors for clinical outcome. J Neurointerv Surg. 2017;9 11:1118-24; doi: 10.1136/neurintsurg-2016-012576.

43. Onose G, Muresanu DF, Ciurea AV, Daia Chendreanu C, Mihaescu AS, Mardare DC, et al. Neuroprotective and consequent neurorehabilitative clinical outcomes, in patients treated with the pleiotropic drug cerebrolysin. J Med Life. 2009;2 4:350-60.

44. Stallard N. Optimal sample sizes for phase II clinical trials and pilot studies. Stat Med. 2012;31 1112:1031-42; doi: 10.1002/sim.4357.

45. Sim J, Lewis M. The size of a pilot study for a clinical trial should be calculated in relation to considerations of precision and efficiency. J Clin Epidemiol. 2012;65 3:301-8; doi: 10.1016/j.jclinepi.2011.07.011.

46. Schulz KF, Altman DG, Moher D, Group C. CONSORT 2010 statement: updated guidelines for reporting parallel group randomised trials. BMJ. 2010;340:c332; doi: 10.1136/bmj.c332.

47. Gladstone DJ, Black SE, Hakim AM, Heart, Stroke Foundation of Ontario Centre of Excellence in Stroke R. Toward wisdom from failure: lessons from neuroprotective stroke trials and new therapeutic directions. Stroke. 2002;33 8:2123-36. 
48. Tuttolomondo A, Pecoraro R, Arnao V, Maugeri R, lacopino DG, Pinto A. Developing drug strategies for the neuroprotective treatment of acute ischemic stroke. Expert Rev Neurother. 2015;15 11:1271-84; doi: 10.1586/14737175.2015.1101345.

49. Zhang L, Chopp M, Meier DH, Winter S, Wang L, Szalad A, et al. Sonic hedgehog signaling pathway mediates cerebrolysin-improved neurological function after stroke. Stroke. 2013;44 7:1965-72; doi: 10.1161/STROKEAHA.111.000831.

50. Hartbauer M, Hutter-Paie B, Windisch M. Effects of Cerebrolysin on the outgrowth and protection of processes of cultured brain neurons. J Neural Transm (Vienna). 2001;108 5:581-92; doi: $10.1007 /$ s007020170058.

51. Catalin B, Rogoveanu OC, Pirici I, Balseanu TA, Stan A, Tudorica V, et al. Cerebrolysin and Aquaporin 4 Inhibition Improve Pathological and Motor Recovery after Ischemic Stroke. CNS Neurol Disord Drug Targets. 2018;17 4:299-308; doi: 10.2174/1871527317666180425124340.

52. Doppler E, Rockenstein E, Ubhi K, Inglis C, Mante M, Adame A, et al. Neurotrophic effects of Cerebrolysin in the Mecp2(308/Y) transgenic model of Rett syndrome. Acta Neuropathol. 2008;116 4:425-37; doi: 10.1007/s00401-008-0407-x.

53. Bornstein NM, Guekht A, Vester J, Heiss WD, Gusev E, Homberg V, et al. Safety and efficacy of Cerebrolysin in early post-stroke recovery: a meta-analysis of nine randomized clinical trials. Neurol Sci. 2018;39 4:629-40; doi: 10.1007/s10072-017-3214-0.

54. Guekht A, Vester J, Heiss WD, Gusev E, Hoemberg V, Rahlfs VW, et al. Safety and efficacy of Cerebrolysin in motor function recovery after stroke: a meta-analysis of the CARS trials. Neurol Sci. 2017;38 10:1761-9; doi: 10.1007/s10072-017-3037-z.

55. Baskys A, Wojtowicz JM. Effects of brain tissue hydrolysate on synaptic transmission in the hippocampus. Pharmacol Biochem Behav. 1994;49 4:1105-7; doi: 10.1016/0091-3057(94)90272-0.

56. Ginsberg MD. Current status of neuroprotection for cerebral ischemia: synoptic overview. Stroke. 2009;40 3 Suppl:S111-4; doi: 10.1161/STROKEAHA.108.528877.

57. Chen S, Feng H, Sherchan P, Klebe D, Zhao G, Sun X, et al. Controversies and evolving new mechanisms in subarachnoid hemorrhage. Prog Neurobiol. 2014;115:64-91; doi:

10.1016/j.pneurobio.2013.09.002.

58. Ayer R, Zhang J. Connecting the early brain injury of aneurysmal subarachnoid hemorrhage to clinical practice. Turk Neurosurg. 2010;20 2:159-66; doi: 10.5137/1019-5149.JTN.2714-09.0.

59. Wostrack M, Sandow N, Vajkoczy P, Schatlo B, Bijlenga P, Schaller K, et al. Subarachnoid haemorrhage WFNS grade V: is maximal treatment worthwhile? Acta Neurochir (Wien). 2013;155 4:579-86; doi: 10.1007/s00701-013-1634-z.

60. van Donkelaar CE, Bakker NA, Veeger NJ, Uyttenboogaart M, Metzemaekers JD, Eshghi O, et al. Prediction of outcome after subarachnoid hemorrhage: timing of clinical assessment. J Neurosurg. 2017;126 1:52-9; doi: 10.3171/2016.1.JNS152136.

61. Wong GK, Lam SW, Ngai K, Wong A, Siu D, Poon WS, et al. Cognitive domain deficits in patients with aneurysmal subarachnoid haemorrhage at 1 year. J Neurol Neurosurg Psychiatry. 2013;84 9:1054-8; 
doi: 10.1136/jnnp-2012-304517.

62. Chu AC, Wong GK, Lam SW, Wong A, Ngai K, Poon WS, et al. Cognitive impairment in aneurysmal subarachnoid hemorrhage patients with delayed cerebral infarction: prevalence and pattern. Acta Neurochir Suppl. 2015;120:303-6; doi: 10.1007/978-3-319-04981-6_51.

63. Chen N, Yang M, Guo J, Zhou M, Zhu C, He L. Cerebrolysin for vascular dementia. Cochrane Database Syst Rev. 2013; 1:CD008900; doi: 10.1002/14651858.CD008900.pub2.

64. Gauthier S, Proano JV, Jia J, Froelich L, Vester JC, Doppler E. Cerebrolysin in mild-to-moderate Alzheimer's disease: a meta-analysis of randomized controlled clinical trials. Dement Geriatr Cogn Disord. 2015;39 5-6:332-47; doi: 10.1159/000377672.

65. Alvarez XA, Cacabelos R, Sampedro C, Aleixandre M, Linares C, Granizo E, et al. Efficacy and safety of Cerebrolysin in moderate to moderately severe Alzheimer's disease: results of a randomized, double-blind, controlled trial investigating three dosages of Cerebrolysin. Eur J Neurol. 2011;18 1:5968; doi: 10.1111/j.1468-1331.2010.03092.x.

\section{Figures}

\section{Figure 1}

Trial patient profile

\section{Figure 2}

Distribution of 6-month GOSE and mRS functional outcomes

\section{Figure 3}

Forest plot. A priori subgroup analysis for favorable GOSE (5 to 8 ) at 6 months. "Events" indicates the number of patients with favorable 6-month GOSE for each subgroup. "Total" indicates the number of patients with a particular characteristic that were assigned to either the Cerebrolysin or Normal Saline (placebo) group. N.B. WFNS, World Federation of Neurosurgical Societies

\section{Supplementary Files}

This is a list of supplementary files associated with this preprint. Click to download.

- CONSORT2010Checklist.doc 